\title{
ILCEA
}

Revue de l'Institut des langues et cultures

d'Europe, Amérique, Afrique, Asie et Australie

$26 \mid 2016$

Mémoire, vérité et justice en Uruguay

\section{La impunidad más allá de la Ley de Caducidad. Construcción de un marco jurídico nacional de derechos humanos vs. persistencia de la cultura de impunidad}

Impunity beyond the Ley de Caducidad. Construction of a National Legal

Framework of Human Rights vs Persistent Culture of Impunity

L'impunité au-delà de la Loi de caducité. Construction d'un cadre légal national

des droits de l'homme vs persistance d'une culture de l'impunité

\section{Mirtha Guianze}

\section{OpenEdition}

\section{Journals}

Edición electrónica

URL: http://journals.openedition.org/ilcea/3916

DOI: $10.4000 /$ ilcea.3916

ISSN: 2101-0609

Editor

UGA Éditions/Université Grenoble Alpes

Edición impresa

ISBN: 978-2-84310-334-6

ISSN: $1639-6073$

\section{Referencia electrónica}

Mirtha Guianze, «La impunidad más allá de la Ley de Caducidad. Construcción de un marco jurídico

nacional de derechos humanos vs. persistencia de la cultura de impunidad », ILCEA [En línea],

26 | 2016, Publicado el 07 julio 2016, consultado el 19 abril 2019. URL : http://

journals.openedition.org/ilcea/3916 ; DOI : 10.4000/ilcea.3916

Este documento fue generado automáticamente el 19 abril 2019.

(C) ILCEA 


\title{
La impunidad más allá de la Ley de Caducidad. Construcción de un marco jurídico nacional de derechos humanos vs. persistencia de la cultura de impunidad
}

\author{
Impunity beyond the Ley de Caducidad. Construction of a National Legal \\ Framework of Human Rights vs Persistent Culture of Impunity \\ L'impunité au-delà de la Loi de caducité. Construction d'un cadre légal national \\ des droits de l'homme vs persistance d'une culture de l'impunité
}

Mirtha Guianze

\section{Breve reseña del significado de la impunidad en la persecución de graves violaciones a los derechos humanos en Uruguay durante la dictadura}

1 Para buscar alguna definición de impunidad, podemos recurrir a la que ha dado la Corte Interamericana de Derechos Humanos, como «la falta en su conjunto de investigación, persecución, captura, enjuiciamiento y condena de los responsables de las graves violaciones de los derechos humanos» recordando que «el Estado tiene la obligación de combatir tal situación por todos los medios legales disponibles ya que la impunidad propicia la repetición crónica de las violaciones de derechos humanos y la total indefensión de las víctimas y sus familiares» (2005).

2 Pero el concepto «impunidad» no describe, en sentido estricto, un asunto legal, sino un fenómeno de dimensiones legales, sociales, culturales, psicológicas y hasta económicas. En términos generales esta puede ser entendida como la ausencia de pena, la no 
punibilidad, o ausencia de castigo, los cuales son una clara oposición a los conceptos ampliamente conocidos de impunibilidad, imputabilidad e inmunidad. Es así que la investigación y castigo de los graves delitos de las dictaduras en los países de América Latina, se vuelve una cuestión ineludible, para la consolidación y fortalecimiento de la democracia (Robles, 2005; 2007).

La naturalización de la impunidad, en el presente, debe pues encuadrarse dentro del mismo contexto en el que se produjeron las graves violaciones a los derechos humanos en el pasado. La obstaculización de la función judicial, impidiendo el acceso a la verdad, al paralizar el mecanismo específicamente idóneo para investigar, impidió también que la justicia ejercitara su función preventiva. El mantenimiento de la impunidad formó parte de la difusión falaz o distorsionada de la historia, de la construcción de un orden social fundado en el desconocimiento del horror. Convivimos en silencio con los perpetradores durante años, al tiempo que se proclamaban las virtudes de la democracia y del «Cambio en Paz», de una transición pacífica y sin rencores, haciendo de esa impunidad de facto un motivo de orgullo nacional.

4 Nuestras dictaduras aparejaron años de horrores compartidos con países del Cono Sur, fruto de la aplicación de la Doctrina de la Seguridad Nacional y al cobijo del Plan Cóndor, que nos hermanó en el padecimiento del terrorismo de Estado.

El sistema democrático, instaurado a partir de 1985, resultó imperfecto, puesto que se pretendió ignorar que la tortura había sido una práctica sistemática en establecimientos militares y policiales, que muchos murieron en medio de los salvajes tormentos, que hubo asesinatos políticos, que hay alrededor de doscientos detenidos desaparecidos y había niños arrebatados a sus madres presas, que los estaban buscando incansablemente.

6 Tal como señalara la Corte Interamericana de Derechos Humanos, en la sentencia del caso «Gelman vs. Uruguay» (2011, parr. 239), la sola existencia de un régimen democrático no garantiza, per se, el permanente respeto del Derecho Internacional, incluyendo al Derecho Internacional de los Derechos Humanos, lo cual ha sido así considerado incluso por la propia Carta Democrática Interamericana. La legitimación democrática de determinados hechos o actos en una sociedad está limitada por las normas y obligaciones internacionales de protección de los derechos humanos reconocidos en tratados como la Convención Americana, de modo que la existencia de un verdadero régimen democrático está determinada por sus características tanto formales como sustanciales, por lo que, particularmente en casos de graves violaciones a las normas del Derecho Internacional de los Derechos, la protección de los derechos humanos constituye un límite infranqueable a la regla de mayorías, es decir, a la esfera de lo «susceptible de ser decidido» por parte de las mayorías en instancias democráticas, en las cuales también debe primar un «control de convencionalidad» (supra párr. 193), que es función y tarea de cualquier autoridad pública y no sólo del Poder Judicial.

7 En este sentido, nuestra Suprema Corte de Justicia ha ejercido ese control de convencionalidad en el caso Nibia Sabalsagaray, al establecer, inter alia, que:

[...] el límite de la decisión de la mayoría reside, esencialmente, en dos cosas: la tutela de los derechos fundamentales (los primeros, entre todos, son el derecho a la vida y a la libertad personal, y no hay voluntad de la mayoría, ni interés general ni bien común o público en aras de los cuales puedan ser sacrificados) y la sujeción de los poderes públicos a la ley. (Sentencia n. ${ }^{\circ} 365 / 2009$ )

Otros tribunales nacionales se han referido también a los límites de la democracia en relación con la protección de derechos fundamentales. Es importante recalcar estos 
conceptos, porque se pretendió legitimar la impunidad, en algunos ámbitos, bajo el pretexto de su ratificación por «voluntad popular».

Muy brevemente, entonces, tenemos que hacer referencia a la situación de Uruguay, relato de algunos hechos relevantes luego de la restauración democrática, porque la transición, que trata de dejar atrás los conflictos del pasado, está aún lejos de consolidarse.

10 Si abordamos el tema Memoria en nuestro país resulta ineludible partir del silencio obligado que siguió a marzo de 1985 y se prolongó durante décadas. Del desconocimiento del terrorismo de Estado y sus cruentos métodos de represión durante ese período, o la tergiversación de los hechos, fundamentalmente desde la órbita gubernamental ${ }^{2}$.

11 En 1984, en la Comisión Nacional Programática (CONAPRO)³, los partidos políticos habían acordado que:

Constituye un grave riesgo para la real vigencia de los Derechos Humanos en el

futuro, mantener a la sociedad uruguaya en la ignorancia respecto de la verdad de

las denuncias referidas y dejar impunes los hechos que constituyen ilícitos penales.

En ese entonces, ya eran muy notorias las atrocidades del régimen, estaban denunciadas internacionalmente y circulaban en todos los ámbitos en forma privada.

Con eso queda claro que hubo preocupación inicial del sistema político, que nadie ignoraba la gravedad del asunto $\mathrm{y}$, por eso mismo, se constituyeron comisiones investigadoras parlamentarias. Sin embargo, el cúmulo de información que recopilaron permaneció sepultado por varios años y recién empezó a ser utilizada en los procesos de 2006 en adelante ${ }^{4}$. Porque las políticas de los gobiernos con relación a los hechos del pasado, se manifiestan en una serie de decisiones que involucran no sólo aspectos jurídicos, sino también procesamiento de datos políticos y presiones externas, del entorno social y de grupos de poder.

Es así que, en cada país y en épocas distintas, de acuerdo a esa puja de fuerzas, hubo avances, retrocesos y aún paralización total de los procesos por verdad y justicia. Procesos que abarcan necesariamente a las instituciones públicas con facultades decisorias (en nuestro caso a los tres poderes, ejecutivo, legislativo y judicial), pero también a las de la sociedad civil, a grupos de poder organizados con incidencia efectiva en las decisiones gubernamentales y a la inevitable repercusión de los medios de comunicación y el mensaje que trasmitan, según el caso (Dutrenit Bielous \& Varela Petito, 2010).

14 El dictado de la Ley de Caducidad de la Pretensión Punitiva del Estado $-\mathrm{n} .^{\circ} 15.848-$ verdadera amnistía encubierta, no hizo sino consolidar una impunidad normativa, cuando fácticamente ésta ya estaba instaurada. Nuestra Ley de Caducidad no responde anl modelo clásico de las denominadas «autoamnistías», porque fue aprobada por un Parlamento electo por el cuerpo electoral (aunque en elecciones con candidatos proscriptos) y luego no fueron suficientes los votos para derogarla por plebiscito popular. Esta apariencia de legitimidad fue uno de los argumentos utilizados para afirmar su vigencia. El Poder Ejecutivo decidía, en cada caso, cuándo una denuncia podía ser investigada, cuándo un proceso podía ser llevado adelante.

15 Pero además, las interpretaciones que de la propia ley hizo el Poder Ejecutivo por sucesivos períodos y la sumisión del sistema de justicia, que no cuestionaba esos informes, supusieron que todas las investigaciones emprendidas, todas las denuncias formuladas, fueran declaradas comprendidas en las disposiciones de la Ley de Caducidad. No hubo 
investigación en la órbita penal, pero tampoco la hubo en la civil, para averiguar la verdad.

Los tres poderes del Estado cumplieron su papel. El sistema de justicia se plegó a la política oficial. La Suprema Corte de Justicia, nombrada en 1985, declaró que la Ley de Caducidad se ajustaba a las normas constitucionales, en un fallo calificado como más político que jurídico (La Justicia Uruguaya, tomo XCVI, 1988). Pero tampoco los tribunales de menor jerarquía se atrevieron a quebrar esa impunidad. Se trataba, en todo caso, solamente de interpretar la ley a tenor de su texto literal, puesto que ésta reconocía límites de carácter personal, por ejemplo, no comprendía a los civiles, precisamente porque fue dictada bajo la amenaza de los militares, que no admitían ser sometidos a juicio. También hubiera correspondido excluir de la aplicación de la Ley de Caducidad los delitos cometidos por los mandos. Se correspondía con la motivación de la Ley de Caducidad, que se habría basado en una especie de obediencia debida, traducida en la expresión: «y en ocasión de acciones ordenadas por los mandos que actuaron durante el período de facto». Asimismo era lógico sostener limitaciones a la aplicación de orden espacial. Las leyes penales tanto las incriminatorias como las despenalizadoras, valen y tienen vigencia para los delitos cometidos dentro del territorio nacional, lo que hubiera llevado a excluir muchos de los crímenes ejecutados en el marco del Plan Cóndor, por ejemplo.

Teníamos también un límite temporal. La ley aclaraba que la fecha de comienzo de su vigencia se corresponde con el período de facto, esto es, el 27 de junio de 1973, día del golpe de Estado, y abarca hasta el $1^{\circ}$ de marzo de 1985. En base a este criterio, quedaron fuera del ámbito de aplicación de la ley, privaciones de libertad y homicidios ocurridos antes del 27 de junio de 1973 perpetrados presuntamente por agentes estatales. Por vía interpretativa pudo sostenerse que los delitos permanentes (llámese privación de libertad o desaparición forzada) se siguen cometiendo actualmente y, por lo mismo, podrían ser perseguidos con independencia de la acotada vigencia de la Ley de Caducidad. La misma ley exceptuó también de la prohibición legal de enjuiciar, a los delitos cometidos en procura de lograr un provecho económico, para sí o para un tercero.

Sin embargo, la impunidad normativa resultó respaldada, sin fisuras por jueces y fiscales durante casi dos décadas. No hubo interpretaciones discordantes que permitieran iniciar juicios. Explicar el papel del sistema de justicia de esa época sería harto complejo. Seguramente el origen podría estar en el sistema de nombramientos, ascensos y traslados de los magistrados, tanto del Poder Judicial como del Ministerio Público y Fiscal y la extracción del personal judicial en el período post dictadura. Pero indudablemente ese análisis excede lo meramente jurídico y corresponde a otras disciplinas. Un sistema judicial que es afín al poder, o cuyos miembros son atemorizados o renuentes a tomar actitudes de confrontación con las opiniones de sus superiores, fuere porque son presionados o sólo porque no quieren ver coartada su carrera ascendente, asegura sin lugar a dudas la aplicación de leyes de amnistía o similares ${ }^{5}$.

Nunca más cierto que:

El retraso de la justicia o una justicia incompleta, constituyen el obstáculo principal para entablar una relación distinta con el pasado. Los procesos judiciales completos y en término establecerán la verdad judicial indispensable pero tampoco suficiente. Habría que agregar la respuesta que el Estado tiene aún pendiente: hallar y difundir la información producida durante el tiempo de la dictadura - los archivos- para dar cuenta de quien, cuando, donde y por qué secuestró, desapareció y asesinó a cada una de las víctimas de entonces. (Tapatá de Valdéz, 2002: 87) 


\section{Situación actual, repercusiones y problemas vigentes}

En nuestro país, a diferencia de lo que ocurrió en otros de la región, las instituciones democráticas no avanzaron en el esclarecimiento de la verdad, aunque se hayan instaurado algunos procesos y haya un cierto número de represores presos y aún condenados. Pero estos represores han persistido en guardar celosamente sus secretos. Claramente, durante mucho tiempo, las políticas de Estado estuvieron dirigidas a impedir la obtención de verdad y justicia. En el año 2000, el Presidente Jorge Batlle constituyó, la llamada Comisión para la Paz, cuyos miembros fueron designados por el propio Presidente, que debía investigar acerca del destino de los desaparecidos. Como resultado positivo puede valorarse que en el informe de la Comisión hubo reconocimiento gubernamental a la existencia de desaparición forzada de personas, como consecuencia de graves violaciones a los derechos humanos ${ }^{6}$. Pero sus actuaciones fueron secretas, no pudieron conocerse las fuentes militares de información y más adelante se supo que los dichos de esos sujetos, en muchos casos fueron las primeras manifestaciones de la «mentira institucional» según expresión del Prof. Alvaro Ricco. En efecto, ya en ese entonces los militares pergeñaron estrategias de ocultamiento, mintiendo sobre el destino de los cuerpos, procurando en definitiva que se desistiera de la búsqueda.

21 En este período de gobierno, el 19 de mayo de 2015 el Presidente Vázquez creó el Grupo de Trabajo por Verdad y Justicia, que tendrá por cometido esencial investigar los crímenes de lesa humanidad cometidos por agentes del Estado o con su aquiescencia entre el 13 de junio de 1968 hasta el 28 de febrero de $1985^{7}$.

Pero hasta el presente, lo realmente valioso ha sido el testimonio de las víctimas y la documentación que pudo hallarse, en el país o en el extranjero, fragmentaria e incompleta, hoy sistematizada en la Secretaría de Derechos Humanos para el Pasado Reciente. No se ha logrado acceder al núcleo duro de la información del Ministerio de Defensa ${ }^{8}$.

23 En la inmensa mayoría de los casos en los que se logró enjuiciar a represores, no pudo avanzarse en la averiguación del destino de los detenidos desaparecidos. Sólo los restos de cuatro víctimas fueron hallados y, en cierto modo, esa recolección de datos se realiza en una esfera ajena al sistema de justicia. En el presente, aún sin haber resuelto ese lastre del pasado, debemos reflexionar sobre la forma en que esa escalada de violencia, esa barbarie, influyó en el tejido social. La naturalización de los métodos represivos violentos, el silenciamiento de la protesta, el desmembramiento de familias por muertes, prisión o exilio, fueron construyendo un país distinto, más violento, que todavía no identificamos, o no reconocemos en su integralidad.

Entonces, teniendo como presupuesto que el reconocimiento de la verdad y la lucha contra la impunidad, constituyen el asiento de la reconstrucción de relaciones sociales sobre bases sanas, de un Estado democrático de Derecho, se impone el análisis de las distintas formas que esa difusión de los hechos históricos y que el funcionamiento del sistema de justicia puede revestir.

Las organizaciones de derechos humanos y los movimientos de víctimas del terrorismo de Estado fueron -y siguen siendo hoy día- el sostén constante de la memoria y de la búsqueda de verdad y justicia. Recordamos que la organización de Madres y Familiares de 
Detenidos Desaparecidos en carta dirigida al Presidente de la República José Mujica, el 27 de abril de 2010, antes de que éste asumiera su cargo, le decían que:

En el centro de nuestra lucha está encontrar a nuestros seres queridos. Al comienzo teníamos la esperanza de encontrarlos con vida. Ahora no, salvo a los niños. Por eso un eje de nuestro trabajo es la investigación junto con la prevención y la memoria como promotores del «nunca más». Ahora bien, nosotros no investigamos como los científicos para conocer lo desconocido. Nosotros investigamos para encontrar algo que es conocido y que perversamente se oculta: la suerte de nuestros familiares. $Y$ estos hechos se ocultan al punto de mentirnos, de mentirle a la sociedad entera y al Presidente de la República. (Madres y Familiares, 2010)

Esos reclamos siguen hoy día. Los mismos Familiares entienden que el Estado no es proactivo en esa política de Memoria, que los proyectos que se van ejecutando son los de las propias organizaciones, que tienen escaso eco en las instituciones destinadas al esclarecimiento de los hechos, a la implementación de esas políticas y a la rectificación de una insuficiente o defectuosa legislación en materia de reparaciones. Sus estrategias se dirigen a incidir, a nivel de organizaciones sociales y a nivel internacional, para que el Estado cumpla con sus obligaciones.

Estas falencias o insuficiencias se manifiestan en la búsqueda útil de información, en los métodos de investigación, en los criterios para dirigir las investigaciones. Las víctimas reclaman personal capacitado y bastante para profundizar las indagatorias, una actitud clara con relación a las Fuerzas Armadas, que continúan ocultando archivos y que no brindan información sobre detenidos desaparecidos. Una afirmación compartible de Madres y Familiares es que si no avanzamos en ese campo, tampoco profundizamos la democracia. Es más, la democracia se daña si la impunidad va consolidándose. En ese mismo contexto se ubica la falta de reglamentación de la Ley de Acceso a la información y las argucias legales que se emplean para eludir la entrega de archivos.

El dictado de la Ley $n .^{\circ} 18.831$, que restableció en su artículo $1^{\circ}$ : «la pretensión punitiva del Estado», pareció resquebrajar la impunidad, al menos en lo que al marco legal restrictivo se refiere. Pero la Sentencia n. ${ }^{\circ}$ 20/2013 de la Suprema Corte de Justicia, y las sucesivas decisiones judiciales en el mismo sentido, que declararon inconstitucionales los artículos $2^{\circ}$ y $3^{\circ}$, reeditaron la utilización de la prescripción de los delitos como obstáculo para la prosecución de los juicios ${ }^{9}$.

La Sentencia del 24/02/2011 en el caso Gelman vs. Uruguay de la Corte Interamericana de Derechos Humanos, ya citada, impone a nuestro país la obligación de investigar con celeridad las denuncias por violaciones a los derechos humanos, no obstaculizar dichas investigaciones y llevarlas adelante por profesionales debidamente especializados y está implementando un seguimiento permanente a la forma en que Uruguay cumple o no los diferentes aspectos de esa sentencia.

Cuando la Corte Interamericana emitió esa condena, hizo hincapié en el prenombrado «control de convencionalidad», concepto acuñado y consolidado en el sistema interamericano, reafirmando que cuando un Estado es Parte, en un tratado internacional como la Convención Americana, todos sus órganos, incluidos sus jueces y demás órganos vinculados a la administración de justicia en todos los niveles, también están vinculados al tratado, lo cual les obliga a velar para que los efectos de las disposiciones de la Convención no se vean mermados por la aplicación de normas contrarias a su objeto y fin, de modo que decisiones judiciales o administrativas no hagan ilusorio el cumplimiento total o parcial de las obligaciones internacionales. La interpretación del control de convencionalidad que hizo nuestra Suprema Corte de Justicia en la Sentencia n. ${ }^{\circ}$ 20/2013 
y las posteriores de igual tenor, es violatoria de las obligaciones contraídas por Uruguay $\mathrm{y}$, como órgano del Estado, nos expone a sanciones posteriores.

31 El grave problema que afrontamos no se limita, sin embargo, a las falencias o erróneas decisiones del Poder Judicial. El Estado es uno, sus tres Poderes están comprometidos en la búsqueda de la verdad y deben desarrollar acciones idóneas para lograr ese fin. La inexistencia de una política de Estado clara, es uno de los factores que ha llevado a estos resultados erráticos e insuficientes. Los desafíos actuales suponen impulsar definiciones de los tres poderes del Estado tendientes a llevar adelante todas las acciones necesarias para que el ordenamiento jurídico y las prácticas administrativas e institucionales se armonicen con los instrumentos internacionales relacionados con derechos humanos de los que el Estado sea parte, promover estrategias para proseguir investigaciones pese a la sentencia de la Suprema Corte, fortalecer la tutela de los derechos humanos a nivel nacional, regional y universal, modificar el sistema de justicia para asegurar recurso efectivo a las víctimas e independencia de los Magistrados, y asegurar métodos de investigación para avanzar en la búsqueda de la verdad.

El adecuado procesamiento del pasado, concretamente de la impunidad, de la justificación de la violencia institucional, compromete nuestro presente. Necesitamos el conocimiento de la verdad, la construcción de memoria, valores y principios que refuercen nuestra institucionalidad. De otra forma, no tendremos autoridad moral para censurar la justificación de la violencia diaria que se entroniza en nuestras sociedades, de manifestar nuestro repudio por la trivialización de ese tipo de manifestaciones a nivel público y en los medios masivos de comunicación.

\section{Persecución de los crímenes de la dictadura perpetrados en el marco del Plan Cóndor en Tribunales nacionales y extranjeros}

La inacción de la justicia en Uruguay impulsó a las víctimas y sus familiares a buscar en otros países lo que les era negado en su tierra. La conexión represiva entre las dictaduras de Argentina y Uruguay supuso que muchos compatriotas sufrieran tortura, prisión, desaparición o muerte en aquel país.

Las alternativas de los juicios por crímenes de lesa humanidad en Argentina han sido diversas, pero ofrecieron a ciudadanos uruguayos la posibilidad de llevar adelante sus denuncias (CELS, 2011). En este momento se está juzgando en Buenos Aires, dentro del proceso por Plan Cóndor, a Manuel Cordero, un militar uruguayo, reconocido torturador, que fue extraditado desde Brasil. Muchos uruguayos estuvieron detenidos en el centro clandestino llamado Automotores Orletti, una de las bases del Plan Cóndor. Los prisioneros que trajeron en el último de los traslados de prisioneros desde esa base a Uruguay, fueron torturados y desaparecidos en nuestro país. Ese caso fue excluido, durante la primera administración de Tabaré Vázquez de la Ley de Caducidad. Se habilitó la investigación y los represores uruguayos fueron enjuiciados y condenados en Uruguay. En Argentina se inició un juicio paralelo para investigar a los argentinos que participaron en los crímenes de Orletti ${ }^{10}$. Testigos y víctimas uruguayos y argentinos han declarado en los juicios de las dos orillas del Río de la Plata.

35 Asimismo, en Italia, en la Corte D’Assise de Roma, se está juzgando a un grupo de militares uruguayos que operaron en Buenos Aires, secuestraron y torturaron a uruguayos, los 
trasladaron clandestinamente a Uruguay y son responsables de la desaparición de veintiocho personas. Esta denuncia fue formulada por familiares de desaparecidos de nacionalidad italiana, ante el Fiscal Giancarlo Capaldo, en 1999. La elevación a juicio se produjo recién en 2014. A esos casos inicialmente denunciados se adjuntó la causa que se sigue al marino Jorge Troccoli, responsable del secuestro en Buenos Aires y la desaparición de treinta y nueve personas.

Troccoli fue investigado y procesado en Uruguay en 2007, pero huyó a Italia, país que le había otorgado la ciudadanía tiempo atrás ${ }^{11}$. En virtud del Tratado de extradición vigente entre Uruguay e Italia, este país no entrega a sus nacionales, pero tiene la obligación de juzgar a la persona requerida.

El juzgamiento de Troccoli representa un hito importante en la lucha contra la impunidad, al igual que el de Cordero en Argentina. Demostró que los criminales pueden ser perseguidos fuera de fronteras, en el país donde intenten refugiarse. El caso de Troccoli implica un desafío enorme porque la prueba debe producirse conforme a la legislación italiana, los testigos deben trasladarse a miles de quilómetros, enfrentar la barrera del idioma, declarar ante un jurado que no conoce la realidad de nuestros países, para los que el Plan Cóndor es algo lejano.

El juicio prosigue, sin embargo, las vivencias trágicas de cada testigo van acercando ese jurado al contexto represivo de aquella época, a la tortura propia o de los compañeros, a la desaparición o la muerte de los seres queridos.

Fui citada a declarar como testigo en ese juicio por la Presidencia del Consejo de Ministros de Italia, el 20 de octubre. Después de una larga declaración de varias horas, se me convocó nuevamente para el 30, fecha en la que volví a prestar testimonio extensamente. La convocatoria se hizo en razón de que fui la Fiscal que investigó los casos, solicitó los procesamientos y siguió todos los juicios hasta su finalización. Puse entonces a disposición del Tribunal todos los elementos probatorios reunidos en Uruguay ${ }^{12}$. Hay muchas esperanzas cifradas dentro del colectivo de víctimas en que finalmente la sentencia condenatoria se dicte y la impunidad se resquebraje, al menos en este caso.

El esfuerzo solidario de todos los testigos, de los familiares, de los antiguos militantes, es un ejemplo de lo que puede hacer la sociedad civil organizada. La búsqueda y aporte de nuevos elementos de prueba, la colaboración espontánea de decenas de personas en estos meses, más allá de lo que el Estado uruguayo pueda oficialmente hacer, ha sido y es determinante en la evolución del proceso.

\section{Fundamentos de la protección, defensa, promoción y protección en toda su extensión de los derechos humanos en el ámbito nacional, reconocidos en la Constitución y el Derecho Internacional}

Planteado este panorama, la introducción de la regulación internacional en materia de derechos humanos, condenatoria de las graves violaciones a los derechos humanos, el respeto que nuestro país manifestó en toda ocasión por esas normas y por los organismos encargados de su aplicación, parecían ser la salida lógica para conflictos que internamente no se habían superado. 
42 Pues bien, la actual postura de nuestra Suprema Corte de Justicia nos coloca en una situación de radical oposición con la jurisprudencia mayoritaria, no sólo de la región, sino de la producción universal. En los últimos tiempos, sin embargo, la integración de la Corte con otros miembros, por ausencia de los titulares, ha producido algún cambio, en una causa al menos. No puede aún afirmarse que sea una tendencia consolidada.

De cualquier manera, entiendo que esta cuestión no se reduce a un debate estrictamente de carácter jurídico. Toda decisión proporciona tanto elementos éticos como jurídicos, porque se inserta y proviene de un contexto social y responde a una determinada demanda de justicia.

El expediente en que se dictó la precitada Sentencia $n .{ }^{\circ} 20$ refería a un caso de torturas y tratos crueles, inhumanos o degradantes infringidos cotidianamente a un grupo de personas en un establecimiento militar, una denuncia colectiva en la que todos los declarantes describían una situación de horror, graves y sistemáticas violaciones a los derechos humanos. Esa situación de horror, por si sola debió, a mi juicio, dar mérito a un análisis de fondo.

Desde la Institución Nacional de Derechos Humanos, cuyo directorio integro, se señaló que la efectiva implementación de las disposiciones contenidas en los tratados de derechos humanos y de las decisiones de los órganos de contralor de las obligaciones internacionales en materia de derechos humanos, es un compromiso de los Estados como pilar fundamental de protección de la dignidad humana.

De ahí que la ejecución real y efectiva en el ámbito nacional de las decisiones internacionales en materia de derechos humanos, construye y fortalece la tutela de los derechos humanos a nivel nacional, regional y universal. Las decisiones que a nivel local menoscaban bajo una $u$ otra manera los avances y obligaciones en esta materia, cercenan el derecho de las víctimas a un recurso efectivo que permita investigar, sancionar y reparar las atrocidades cometidas por conductas graves internacionalmente reconocidos a las víctimas. Asimismo significa una orientación de política judicial que deja de lado parte fundamental de los desarrollos, compromisos, y mandatos provenientes del derecho internacional de los derechos humanos. La Alta Comisionada de Naciones Unidas para los Derechos Humanos expresó preocupación que se «puedan restablecer las sombras de la impunidad en un país que ha comenzado a conciliarse con la verdad y la justicia, para el pleno cumplimiento de sus obligaciones derivadas del derecho internacional» (Navi Pillay, 2012).

47 Muchos tribunales a nivel continental han considerado la jurisprudencia y doctrina del sistema interamericano ya sea como guía y fuente de interpretación de los mandatos constitucionales, como pauta interpretativa mandatoria, como pauta de la existencia de una costumbre internacional que obliga al Estado o, al menos, un criterio relevante de interpretación de los derechos constitucionales.

Siendo que los tratados de derechos humanos se consideran incorporados a la Constitución uruguaya a través de los artículos 72 y 332, en caso de conflicto normativo, éste debe ser resuelto en virtud del principio de favorabilidad o pro-homine según la cual se debe aplicar la norma más favorable a la protección de los derechos humanos. La fuerza jurídica interna de la legislación y jurisprudencia internacional exige un nuevo esfuerzo de los poderes con responsabilidad en el tema, de modo de buscar los caminos para incorporar e interpretar clara y definitivamente dichas obligaciones a nivel local. La falta de incorporación al derecho interno de las obligaciones asumidas en el marco del 
derecho internacional de los derechos humanos y la no implementación eficaz de las decisiones emanadas de los órganos de supervisión, implica un quiebre del compromiso de garantía y reparación a las víctimas de graves violaciones a los derechos humanos, a los que Uruguay se comprometió por múltiples tratados en la materia y en base al principio de buena fe y garantía colectiva de protección de los derechos humanos a nivel universal.

Así, en virtud del artículo 63.1 de la Convención Americana sobre Derechos Humanos y de la interpretación de la teoría de la responsabilidad internacional, la Corte Interamericana de Derechos Humanos ha determinado medidas reparatorias que tienden a resolver las causas últimas de las violaciones cometidas y prevenir violaciones futuras ${ }^{13}$. Entre ellas la persecución penal frente a graves violaciones a los derechos humanos constituye una garantía de los derechos de las víctimas y a su vez, una medida de reparación ${ }^{14}$. La opinión dominante (opinio iuris) - partiendo de un principio general de derecho ${ }^{15}$ - ha establecido que la violación de ciertos derechos debe ser penalizado (Ambos, 1997: 272). A su vez, del estadio de desarrollo del derecho penal internacional vigente, se puede derivar un enunciado legal que establece que las graves violaciones a los derechos humanos imponen la obligación del Estado de penalizarlas.

51 Nuestro país ha ratificado todos los instrumentos internacionales garantizadores de los derechos humanos y sus respectivos protocolos. Por consiguiente, está comprometido a respetar solemnemente sus obligaciones y compatibilizar su derecho interno con los textos a los que se ha obligado. Esta obligación alcanza a sus tres Poderes y no podría jamás, uno de ellos, alegar que su independencia funcional respecto de los otros dos, lo desliga de tales compromisos.

Uruguay, mediando actuación destacable de su Cancillería, se sobrepuso a un retraso de varios años y cumplió con la presentación de todos los informes a los respectivos Comités, dando cuenta de su actuación en materia de derechos humanos ante los organismos competentes.

En 2014 nuestro país se sometió por segunda vez al Examen Periódico Universal y aceptó la totalidad de las observaciones.

Tanto las organizaciones de la Sociedad Civil como la Institución Nacional de Derechos Humanos presentamos en esas instancias nuestros propios informes, diferenciados de los del gobierno y señalando aquellos aspectos que entendimos necesario resaltar ${ }^{16}$.

El relator especial de las Naciones Unidas para la promoción de la Verdad, Justicia y Reparación, Pablo de Greiff, que estuvo en Uruguay desde el 30 de setiembre al 4 de octubre de 2013, en su presentación de las observaciones preliminares, manifestó que el país está comprometido con el respeto a los derechos humanos y que en los últimos diez años se han acelerado las iniciativas para avanzar en la materia, pero advirtió que hay que preguntarse si se están realizando en forma suficiente.

De Greiff recordó que Uruguay es el país con más detenidos y torturados per cápita durante el período dictatorial, señalando que es necesario además de fortalecer los esfuerzos por conocer la verdad de los detenidos desaparecidos aumentar la atención de las víctimas de detención y tortura, incluyendo los casos de abuso sexual contra hombres y mujeres.

57 Otro de los temas tratados fue el acceso a los archivos de la dictadura, donde encontró dificultades, particularmente en los documentos de las Fuerzas Armadas: 
Queda todavía camino por recorrer en este último campo, pues no se cuenta con todos los archivos relevantes especialmente de las Fuerzas Armadas, que, vale decirlo como todos los otros, son propiedad y deberían estar abajo el control de la nación.

El relator especial de Naciones Unidas, señaló también su preocupación por lo que calificó como «un cambio de rumbo» por parte de la Suprema Corte de Justicia, luego que en 2009 determinara la inconstitucionalidad de la Ley de Caducidad para el caso Nibia Sabalsagaray.

«Nada parece amenazar más las posibilidades de progreso en el área de Justicia que decisiones recientes de la Suprema Corte de Justicia. Estas decisiones han despertado alarma tanto en el Uruguay como en la comunidad internacional», señaló, agregando que la decisión de la Corte que considera

[...] inconstitucionales los artículos 2, 3, y 4 de la ley que restablece la pretensión punitiva del Estado y en el curso de la decisión adopta posiciones que claramente no coinciden con tendencias jurisprudenciales actuales manifiestas por decisiones de cortes en distintas partes del mundo.

Mantuvo entrevistas con organizaciones de la sociedad civil y con la INDDHH y en el informe que recientemente elevó al gobierno, abordó precisamente los problemas suscitados por la aplicación de la Ley de Caducidad, los impedimentos para acceder a la justicia, los mecanismos para acceder a la verdad, los archivos y el acceso a la información, el tema de Reparaciones, las garantías de no repetición y las reformas legislativas pendientes.

Consideramos altamente positivo que nuestro país haya asumido la necesidad de fortalecer los sistemas regionales y universales de protección de los derechos humanos, los que fueron creados para asegurar la protección de los individuos en su dignidad y el escrutinio de los Estados en su comportamiento. Debemos procurar entonces, que los dictámenes de esos instrumentos de contralor puedan contribuir eficazmente al fortalecimiento del Estado de derecho, en tanto mecanismos que prioricen la mayor protección de los derechos humanos y el firme compromiso del Estado de garantizar colectivamente su resguardo.

61 Acerca de los temas que nos ocupan, la INDDHH emitió declaraciones en los momentos de mayor riesgo de vulneración de derechos, entre las que creo conducente destacar la que se dio a conocer luego del traslado de la Jueza Mariana Mota, sobre administración de justicia y derechos humanos, en uno de cuyos párrafos se decía:

En concreto: las normas internacionales en materia de independencia del Poder Judicial establecen una serie de estándares para los nombramientos y la permanencia en el cargo, y las mismas enfatizan en que «una de las prácticas que afectan la independencia o imparcialidad del Poder Judicial es el sistema de ascensos o movilidad. Los Principios Básicos Relativos a la Independencia de la Judicatura establecen que los criterios deben ser objetivos. En la misma dirección se pronuncia el Estatuto del Juez Iberoamericano, cuando establece que la estabilidad en el cargo es una garantía esencial de la independencia judicial y las decisiones de ascenso deben estar basadas en los mismos criterios objetivos que para la designación, y deben ser el resultado de un procedimiento transparente y equitativo. Esa es la orientación de los principios y guías sobre independencia de la administración de justicia, así como las observaciones de los Relatores y del Comité de los Derechos Humanos, que refieren a que la selección, permanencia y remoción de jueces y juezas debe estar asegurada además por un órgano independiente e imparcial representado en parte sustantiva por jueces, abogados y académicos». (Declaración de la INDDHH, 2013, § 13) 

estándares mencionados y lo mismo hemos recomendado al Parlamento con relación al Código del Proceso Penal, para posibilitar un acceso efectivo a la justicia. Tales postulados los hemos mantenido en los informes presentados ante los organismos internacionales. multitudinarias Marchas del Silencio, que se realiza todos los 20 de Mayo, el cartel que encabezada llevaba la leyenda: «En mi patria no hay justicia. ¿Quiénes son los responsables?»

Pues todos lo somos, todos los que no hagamos los máximos esfuerzos para encontrar la verdad, porque no es un derecho de las víctimas y sus familiares lo que se trata de lograr, es de la sociedad toda. La responsabilidad del Estado, como garante de los derechos de las personas, en el que recae la obligación de definir políticas públicas en materia de memoria, verdad y justicia, debe afianzarse en la conciencia colectiva y en el compromiso que debemos asumir como sociedad.

\section{BIBLIOGRAFÍA}

Ambos Kai (1997), Impunidad y Derecho Penal Internacional, 1. a Edición colombiana.

CÁmARA De Representantes, Diario de Sesiones XLII legislatura, Tercer Período Ordinario, 51. ${ }^{\mathrm{a}}$

Sesión, martes 13 de octubre de 1987, n. ${ }^{\circ}$ 1968, Tomo 631, pp. 537-554, Archivo de la Secretaría de Seguimiento de la Comisión para la Paz, Carpeta n. ${ }^{\circ} 06 / 89$.

CELS (2011), Hacer Justicia. Nuevos debates sobre el juzgamiento de crímenes de lesa humanidad en Argentina, Buenos Aires: Siglo Veintiuno Editores.

DANSILIO Florencia \& MERKLEN Denis (2014), «L'Uruguay de José Mujica», Cahiers des Amériques latines, 77, <http://cal.revues.org/3362>.

Dutrénit Bielous Silvia \& Varela Petito Gonzalo (2010), Tramitando el pasado, Violaciones de los derechos humanos y agendas gubernamentales en casos latinoamericanos, Mexico: Flacso.

Dutrénit Bielous Silvia \& Varela Petito Gonzalo (2012), Violaciones a los derechos humanos y agendas gubernamentales en casos latinoamericanos, México: Flacso.

Fondo UniVERsitario PARA CONTRIBUIR A LA COMPRENSIÓN PÚBLICA DE TEMAS DE INTERÉS GENERAL (2014), Uruguay: una muralla impide la plena vigencia de los derechos humanos. Nuestro país no acata los fallos de la Corte Interamericana de Derechos Humanos, Montevideo: CSIC.

InSTITUCión NACIONAL De DeRechos Humanos (2013), Declaración sobre administración de justicia y derechos humanos, <www.cainfo.org.uy/2013/02/declaracion-de-la-institucion-nacional-dederechos-humanos-sobre-administracion-de-justicia-y-derechos-humanos> (consultado el 21/01/2016).

Madres y Familiares de Detenidos Desaparecidos de Uruguay (2010), Comunicado al Presidente de la República, 27/04/2010, <http://desaparecidos.org.uy/wp-content/uploads/2015/06/2010.04.27Carta-publ.-al-Sr.-Presidente-27.4.pdf> (consultado el 21/01/2016). 
MELGAR HourCADE Florencia (2006), Sabotaje a la verdad, Buenos Aires: Planeta.

Naciones Unidas - Oficina de Alto Comisionado Derechos Humanos (2012), Comunicado de la Alta Comisionada de Naciones unidas para los Derechos Humanos, Navi Pillay de 24 de febrero de 2012, <http://acnudh.org/paises/uruguay/> et <www.ohchr.org/SP/countries/LACRegion/ Pages/UYIndex.aspx> (consultado el 21/01/2016).

Revista La Justicia Uruguaya, caso 10.997, tomo XCVI, Sentencia n. ${ }^{\circ}$ 184/88 de 2/5/88.

Rico Álvaro (coord.) (2007-2011), Investigación histórica sobre detenidos desaparecidos, Montevideo, < http://archivo.presidencia.gub.uy/_web/noticias/2007/06/2007060509.htm> (consultado el 21/01/2016).

Suprema CoRte de Justicia de Uruguay (2009), Sentencia n. ${ }^{\circ}$ 365/2009, autos «Sabalsagaray Curutchet, Blanca Stela, Denuncia, Excepción de Inconstitucionalidad, Artículos 1, 3 y 4 de la Ley n. ${ }^{\circ}$ 15.848», Ficha n. ${ }^{\circ}$ 97.397/2004», 19 de octubre de 2009, Publicación del Ministerio de Educación y Cultura, Montevideo: IMPO, <www.poderjudicial.gub.uy>.

TAPATA DE VALDEZ, Patricia (2002), Verdad, Justicia y Reparación. Desafíos para la democracia y la convivencia social, Lima: Instituto Interamericano de Derechos Humanos.

Troво Claudio (2004), Asesinato de Estado, Montevideo: Ed. del Caballo Perdido.

VentuRA Robles Manuel E. (2005), «La Jurisprudencia de la Corte Interamericana de Derechos Humanos en materia de acceso a la Justicia e Impunidad» en el tema «Acceso a la Justicia e Impunidad» del «Taller Regional sobre Democracia, Derechos Humanos y Estado de Derecho», invitado por la Oficina del Alto Comisionado de las Naciones Unidas para los Derechos Humanos (OACDH), 5 y 7 de septiembre de 2005.

VENTURA RoBles Manuel E. (2007), «Texto V», Estudios sobre el sistema interamericano de protección de los derechos humanos, San José de Costa Rica: Ed. Manuel E. Ventura.

\section{NOTAS}

1. El caso Gelman vs. Uruguay es el único en que Uruguay fue condenado por la Corte Interamericana. Macarena Gelman nació en cautiverio en un centro clandestino de Uruguay, luego de que los militares secuestraran a sus padres en Argentina, con su madre embarazada. Su madre María Claudia García Iruretagoyena fue trasladada a Uruguay y permanece desaparecida. Macarena fue robada siendo bebé y entregada a una pareja que la adoptó; recuperó la identidad de sus padres biológicos en 2000 y conoció entonces su historia. Julio María Sanguinetti negó en un intercambio epistolar al poeta Juan Gelman, abuelo de Macarena que la buscaba, la existencia del robo de bebés en el Uruguay. Ver Dutrénit Bielous \& Varela Petito (2012).

2. La llamada dictadura cívico-militar terminó en 1985 con la elección de Julio María Sanguinetti, del Partido Colorado, a la presidencia de la República. Con mayoría del Partido Colorado y del Partido Nacional, el Parlamento votó en 1986 la Ley n. ${ }^{\circ} 15.848$ llamada Ley de «Caducidad de la Pretensión Punitiva del Estado». Pieza fundamental de la transición, la ley ha sido denunciada como una verdadera ley de impunidad protegiendo a los militares autores de ciertos crímenes y volviendo muy difícil la investigación. A través de sendos referéndums, los movimientos de derechos humanos, la central sindical (PIT-CNT) y las fuerzas de izquierda reunidas en el Frente Amplio intentaron revocar la Ley n. ${ }^{\circ} 15.848$ en 1989 y anular una parte de su articulado en 2007. En ambas oportunidades los movimientos sociales perdieron las consultas electorales. Con la conquista del poder por parte del Frente Amplio, el parlamento intentó nuevamente revocar la 
ley bajo el gobierno de José Mujica, proceso que culminó con la sanción de la Ley n. ${ }^{\circ} 18.831$. Ver Dansilio \& Merklen (2014).

3. La Comisión Nacional Programática (CONAPRO) fue un acuerdo firmado por los cuatro principales partidos políticos del Uruguay en 1984 (Partido Colorado, Partido Nacional, Frente Amplio y Unión Cívica) en vistas a organizar la transición a la democracia y de organizar las elecciones presidenciales de 1985.

4. En 1985 se instaló la Comisión Investigadora Parlamentaria sobre situación de personas desaparecidas y hechos que la motivaron, Cámara de Representantes. El informe Final y conclusiones se ubican en el Tomo IV de la Investigación Histórica sobre detenidos desaparecidos, en cumplimiento del artículo $4^{\circ}$ de la Ley . $^{\circ}$ 15.848. En el mismo año, la Comisión Investigadora sobre secuestro y asesinatos perpetrados contra los ex legisladores Héctor Gutiérrez Ruiz y Zelmar Michelini, ocurridos en 1976. Al respecto puede verse: Melgar Hourcade, 2006; Trobo, 2004; Informes finales, Cámara de Representantes, Diario de Sesiones XLII legislatura, Tercer Período Ordinario, 51. ${ }^{a}$ Sesión, martes 13 de octubre de 1987, n. ${ }^{\circ}$ 1968, Tomo 631, pp. 537-554, Archivo de la Secretaría de Seguimiento de la Comisión para la Paz, Carpeta n. ${ }^{\circ}$ 06/89.

Muchos años más tarde, en 1990, se instaló en el Senado una Comisión Investigadora con el objeto de investigar la responsabilidad del Canciller de la dictadura, Juan Carlos Blanco en el secuestro y desaparición de la maestra Elena Quinteros, acaecido en 1976. Blanco era Senador en esa época, fue procesado en 2002 y luego condenado. El Senado no determinó, en 1990, ninguna responsabilidad, para Blanco, la denuncia penal fue formulada por los legisladores del Frente Amplio.

5. Las desviaciones del modelo hegemónico han sido penalizadas por el propio sistema judicial. En 1997, el entonces Juez de Primera Instancia en lo Penal de $14^{\circ}$ Turno, Dr. Alberto Reyes ante una petición del Senador Rafael Michelini, resolvió investigar la existencia de enterramientos clandestinos en predios militares. La información había sido proporcionada a Michelini por un General retirado. Luego de que el Tribunal de alzada revocara la decisión de Reyes, éste fue trasladado a un juzgado civil y el magistrado que lo sustituyó, no retomó la indagatoria. Similar situación se dio cuando el Juez Dr. Alejando Recarey, a cargo del Juzgado de Primera Instancia en lo Penal de $1^{\circ}$ Turno, ordenó la inspección de predios militares en 2003, en el curso de la investigación del destino de la maestra Elena Quinteros, que había determinado el procesamiento de Juan Carlos Blanco y dispuso, además, la citación de militares retirados. Fue apartado de la encargatura antes de que pudieran concretarse esas diligencias y destinado después a un juzgado de la materia civil. En época más reciente, en el año 2013, la Dr. ${ }^{a}$ Mariana Mota, Jueza Penal de $7^{\circ}$ Turno, fue trasladada intempestivamente a un juzgado de la materia civil. Ver Bouvet (2013).

6. Pueden consultarse detalles sobre la Comisión para la Paz en el sitio de la presidencia de la República del Uruguay: <www.presidencia.gub.uy>. El informe final de la Comisión se encuentra

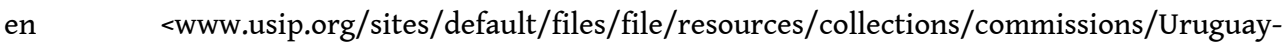
Report_Informal.pdf> (consultado el 21/01/2016).

7. Está integrado por siete personas designadas por el Poder Ejecutivo, entre ellos una representante de Madres y Familiares, una hija de desaparecidos y un hijo de un asesinado político. A la fecha, transcurridos varios meses desde su instalación, no han hecho públicos sus planes de trabajo y líneas de acción. El Decreto de creación no le asigna potestades especiales para el cumplimiento de sus cometidos. La Secretaría de Derechos Humanos para el Pasado Reciente es su soporte funcional y administrativo. Decreto disponible en línea en <http:// archivo.presidencia.gub.uy/sci/decretos/2015/05/cons_min_118.pdf>.

8. La Secretaría de Derechos Humanos para el Pasado Reciente es la encargada de la custodia y administración de toda la documentación disponible en materia de graves violaciones a los derechos humanos en dictadura. Actualmente su Directora, la Licenciada Isabel Wschebor ha dispuesto una mayor apertura, procurando eliminar las prácticas de secretismo que la habían 
caracterizado en el pasado, lo que permite abrigar mejores expectativas en la búsqueda de la verdad. Se trata, no obstante, de un esfuerzo personal, no de una política pública definida.

9. En noviembre de 2011 el Parlamento dictó la Ley $n .^{\circ} 18.831$, por la que se restablece la Pretensión Punitiva del Estado, dejando así sin efecto el artículo $1^{\circ}$ de la Ley de Caducidad. En sus artículos $2^{\circ}$ y $3^{\circ}$ estableció normas para evitar la prescripción de los crímenes cometidos durante la dictadura. La Suprema Corte de Justicia declaró que esos dos últimos artículos son inconstitucionales, lo que impediría la prosecución de los juicios. Ver al respecto: Fondo Universitario para contribuir a la Comprensión Pública de Temas de Interés General (2014).

10. Los juicios seguidos en Uruguay sobre la base de Automotores Orletti fueron: Expediente $n .^{\circ}$ 98- 247/2006, Juzgado Letrado de Primera Instancia en lo Penal de $19^{\circ}$ Turno, Gavazzo Pereira José y Arab Fernández José, Veintiocho delitos de homicicio muy especialmente agravados en reiteración real. Expediente $n .^{\circ}$ 2/43332/2005, Juzgado Letrado de Primera Instancia en lo Penal de $19^{\circ}$ Turno, Jorge Silveira Quesada, Ernesto Ramas Pereira, Ricardo Medina Blanco, Gilberto Vázquez Bissio, Luis Alfredo Maurente, José Sande Lima, veintiocho delitos de homicidio muy especialmente agravados en reiteración real Expediente n. ${ }^{\circ} 98-212 / 2010$, Juzgado Letrado de Primera Instancia en lo Penal de $19^{\circ}$ Turno, Soca Prado, Ernesto, Coautor de veintiocho delitos de homicidio muy especialmente agravados, En esos expedientes se solicitó la extradición de Manuel Cordero. Sentencias disponibles en línea en <www.poderjudicial.gub.uy>.

11. La extradición de Troccoli fue solicitada en el Expediente $n .^{\circ} 2-20415 / 2007$, Juzgado Letrado de Primera Instancia en lo Penal de $19^{\circ}$ Turno, Gregorio Conrado Alvarez Armellino, coautor de treinta y nueve delitos de homicidio muy especialmente agravados, Juan Carlos Larcebeau, coautor de veinticinco delitos de homicidio muy especialmente agravados. Todas las sentencias están disponibles en línea en <www.poderjudicial.gub.uy>.

12. El seguimiento de los juicios en Italia puede hacerse en línea en <www.24marzo.it> o en directo en Radio Radicale. La carátula del expediente es Arce Gómez Luis +32.

13. El principio de efectividad de la protección internacional, lo ha expresado la Corte estableciendo que «[...] los Estados Partes en la Convención deben garantizar el cumplimiento de las disposiciones convencionales y sus efectos propios (effet utile) en el plano de sus respectivos derechos internos. Este principio se aplica no solo [a las normas sustantivas] sino también en relación con las normas procesales [...]» de manera que se proteja practica y eficazmente los derechos. Ver Corte IDH, Caso Baena Ricardo y otros, Cumplimiento de Sentencia, 28 de noviembre de 2005, Considerandos, párrafo 6.

14. Desde la sentencia sobre el caso Velásquez Rodriguez, de 29 de julio de 1998, la Corte Interamericana de Derechos Humanos ha establecido el deber de investigar, juzgar, castigar y reparar.

15. Estatuto de la Corte Internacional de Justicia, articulo 38 I c.

16. Todos los informes presentados, declaraciones y recomendaciones de la Institución Nacional de Derechos Humanos (INDDHH) están disponibles en línea en <www.inddhh.gub.uy>. Véase en especial: Declaración de la INDDHH sobre las obligaciones del Estado en el cumplimiento de la sentencia Gelman vs. Uruguay; Declaración de la INDDHH sobre Fundamentos de la protección de los DDHH en el ámbito nacional, Declaración de la INDDHH sobre administración de justicia y derechos humanos, esta última emitida en ocasión del traslado de la Dr. ${ }^{a}$ Mariana Mota. 


\section{RESÚMENES}

Después de un repaso de la historia del proceso de justicia transicional en Uruguay y de un panorama actual, enfocado en el papel que hubiera podido y debería cumplir el Poder Judicial uruguayo con respecto a la gestión de los crímenes del terrorismo de Estado, se mencionarán las consecuencias de las posturas adoptadas en los últimos años por dicha institución, en clara contradicción con las obligaciones internacionales que se imponen a todos los poderes estatales.

This paper reviews the history of the Uruguayan transitional justice process up to nowadays, focusing on the role that could have been-and should be-played by the Uruguayan judicial branch regarding the management of the crimes of State terrorism. It then presents the consequences of the positions taken in recent years by this institution, which appear in clear contradiction with international obligations that are imposed on all state powers.

Cet article passe en revue l'histoire du processus de justice transitionnelle en Uruguay jusqu'au panorama actuel en se centrant sur le rôle qu'aurait pu et devrait jouer le pouvoir judiciaire uruguayen par rapport à la gestion des crimes du terrorisme d'État. Il est ensuite fait mention des conséquences des postures adoptées ces dernières années par l'institution judiciaire, en soulignant leur contradiction vis-à-vis des obligations internationales qui s'imposent à l'ensemble des pouvoirs étatiques.

\section{ÍNDICE}

Palabras claves: impunidad, Uruguay, Poder Judicial, derechos humanos

Mots-clés: impunité, Uruguay, pouvoir judiciaire, droits de l'homme

Keywords: impunity, Uruguay, judicial branch, human rights

\section{AUTOR}

\section{MIRTHA GUIANZE}

Dr. a, Institución Nacional de Derechos Humanos 